\title{
AFGHANISTAN AFTER NATO WITHDRAWAL
}

\author{
Laviniu BOJOR* \\ laviniu.bojor@yahoo.com \\ Mircea COSMA** \\ mircea.cosma@uamsibiu.ro \\ * "NICOLAE BĂLCESCU" LAND FoRCES ACADEMY, SiBIU, ROMANIA \\ ** “Alma MATER" UNIVERSITy, SibIU, Romania
}

\begin{abstract}
The conclusion of a conflict, called by some American analysts as "America's Longest War", after the withdrawal of the majority of NATO military forces, requires a careful analysis of the conditions and security environment that ISAF mission, International Security Afghan Forces, leaves as legacy to the Afghan military forces. The transfer of authority towards a strong government, recognized by most Afghan provinces, and benefiting from the support of national military forces able to cope with terrorist and insurgent threats on its own, are the minimum and necessary conditions leading the country towards a stable and secure environment and towards a sustainable development. Given these realities, any approach on the consequences of the transition towards self-sustainable governance becomes interesting and timely for any military political study. These are the prospects that we propose in our paper.
\end{abstract}

\section{Keywords}

Afghanistan, NATO withdrawal, irregular conflict, hybrid warfare, Afghan security forces

\section{Introduction}

The refusal of the Taliban regime in Afghanistan to hand over Osama Bin Laden, the leader of the terrorist group responsible for the attacks of September 9, 2001, led to the start of a war that has attracted an International Coalition of over 50 member states in Afghanistan. Given the mandate of the United Nations, the main objective of the ISAF forces was to achieve a secure environment in Afghanistan and to support the Afghan government in its efforts towards the country's reconstruction and in the fight against terrorism.

\section{The Military Intervention}

The operations carried out led to the fall of the Taliban regime and of the leaders 
of this group which chose to retire in Pakistan, along with members of the terrorist group Al Qaeda, far from the reach of international forces. This was followed by a lull, relatively peaceful period, during which there were no large-scale military actions, but which was marked by an intense exploratory campaign for recognition and cautious attempts, carried out outside the border, by anti-government groups in order to identify the weaknesses of the military forces, too strong to be confronted directly. The year 2003, marked by the taking over of the military actions by ISAF - International Security Afghan Forces - finds the country in an environment of relative physical security, due to the protection offered exclusively by international military forces, but lacking measures and conditions in the economic, social, health or education domains, so necessary for national reconstruction.

The lack of jobs and legal conditions for a decent living, was identified as an important link exploited by insurgent groups since 2003, during which drugs became a basic job of Afghan farmers. Efforts to restore national security structures were unsuccessful, the armed forces being too poorly equipped and unprepared to act alone and the police were not credible, because of the intense action of corruption or abuse recorded.

Amid these shortcomings, in the period 2003-2009, the actions of the anti-government forces moved inside Afghanistan and formed networks for the growing and selling of drugs and led intense recruitment campaign using the financial resources obtained from the sale of opium. Their increased power increased, while the insurgent attacks became more frequent every year. In 2009, the environment of insecurity and the insufficient number of ISAF required sending additional forces to reduce the influence of the socalled "Taliban momentum".

At the end of 2014, after 13 years of foreign military support, ISAF mission ends and most international military forces withdraw. Stability efforts are transferred on the shoulders of the Government of the Islamic Republic of Afghanistan and ANSF
- Afghan National Security Forces. The new mission, Resolute Support Mission, reduces the external support to training missions, advice and assistance for the government authorities and security forces, supporting their efforts to avoid the collapse of the country and return to the conditions in 2001 .

The capacity of the government authorities to cope with the insurgent pressures depends heavily on the military, economic and social political conditions existing at the time of the withdrawal of the main external support. To accurately identify them, it is necessary to resort to a tool used by the US Congress to identify the effectiveness of the military actions financed from the American state budget, of the losses, fraud or abuse recorded during the operations undertaken for the reconstruction of Afghanistan: SIGARS Report - Special Inspector General for Afghanistan Reconstruction.

\section{The Current Economic Situation}

The economic development of Afghanistan to a of self-financing of its political and military efforts initiated during the ISAF presence is a prerequisite for maintaining a stable environment in the region, and the increase of the gross domestic product by an average of $9 \%$ [1] per year from 2001 to present is real evidence that this is possible.

Given that Afghanistan has not developed a modern economic infrastructure, able to provide jobs, and because of the fact that it lacks natural resources, unlike Iraq or the Middle East countries, or because it failed to form a stable environment, favourable to foreign investors, the agricultural development programs remain the only viable option for economic growth.

Nonetheless, the information about illicit agriculture remains the main problem of Afghanistan. The SIGARS report concludes that in the last quarter of 2014 the narcotics-based economy makes Afghanistan remain in the top drug-producing countries, as over $90 \%$ of the global opium is cultivated on Afghan land [2]. Opium, morphine and heroin, products derived from opium poppy crops, play a decisive role in the domestic 
economy, the value estimated to leave the country being of approx. 3 billion. It provides 411,000 full-time jobs, more than the total Afghan Security Forces, ANSF [3]. The concern arises from the fact that the total area cultivated has increased since 2002 until the present, reaching a historical threshold of 209,000 hectares, given that in 1999, during the Taliban regime, only 91,000 hectares were used for growing "poppy".

Based on the successful model promoted by the governor of Helmand province in 2008-2010, the foundations of projects known as "ZONE FOOD PROGRAM" were laid. This approach is intended to reduce poppy cultivation and offer legal alternatives to the Afghan population. The strategy includes the following directions:

- Carrying out an intense public campaign to inform the population;

- Encourage alternative crops to reduce dependence on illegal crops; crops;

- Increase of the eradication of illegal

- Expanding drug reduction programs in neighbouring regions.

This program complies with the steps of the INK SPOT strategy, which aims to create a zone in which illegal crops are replaced by other food crops (such as wheat) and these measures are subsequently to expand from year to year in all neighbouring regions.

The population information campaigns are using all necessary means specific to the national culture, in order to transmit the information to the target audience: with the help of the religious leaders, Shura-type meetings, radio or TV messages, distributing promotional materials etc.

Encouraging alternative crops includes not only educating people about the alternatives (such as spices or medical cultures) but also the support for the development of irrigation systems, means of transport, storage or disposal of products on the domestic market or their export.

The eradication of crops includes the destruction of existing ones, and also measures to ban new poppy crops. Unfortunately, this stage depends on the existence of large financial resources and the reality shows that the efforts to combat illegal crops from 2002 to 2013 recorded only temporary results (Figure no. 1).

FLUCTUATIONS IN OPIUM-POPPY CULTIVATON AND KEY EVENTS IN AFGHANISTAN, 2002-2013 (THOUSANDS OF HECTARES)

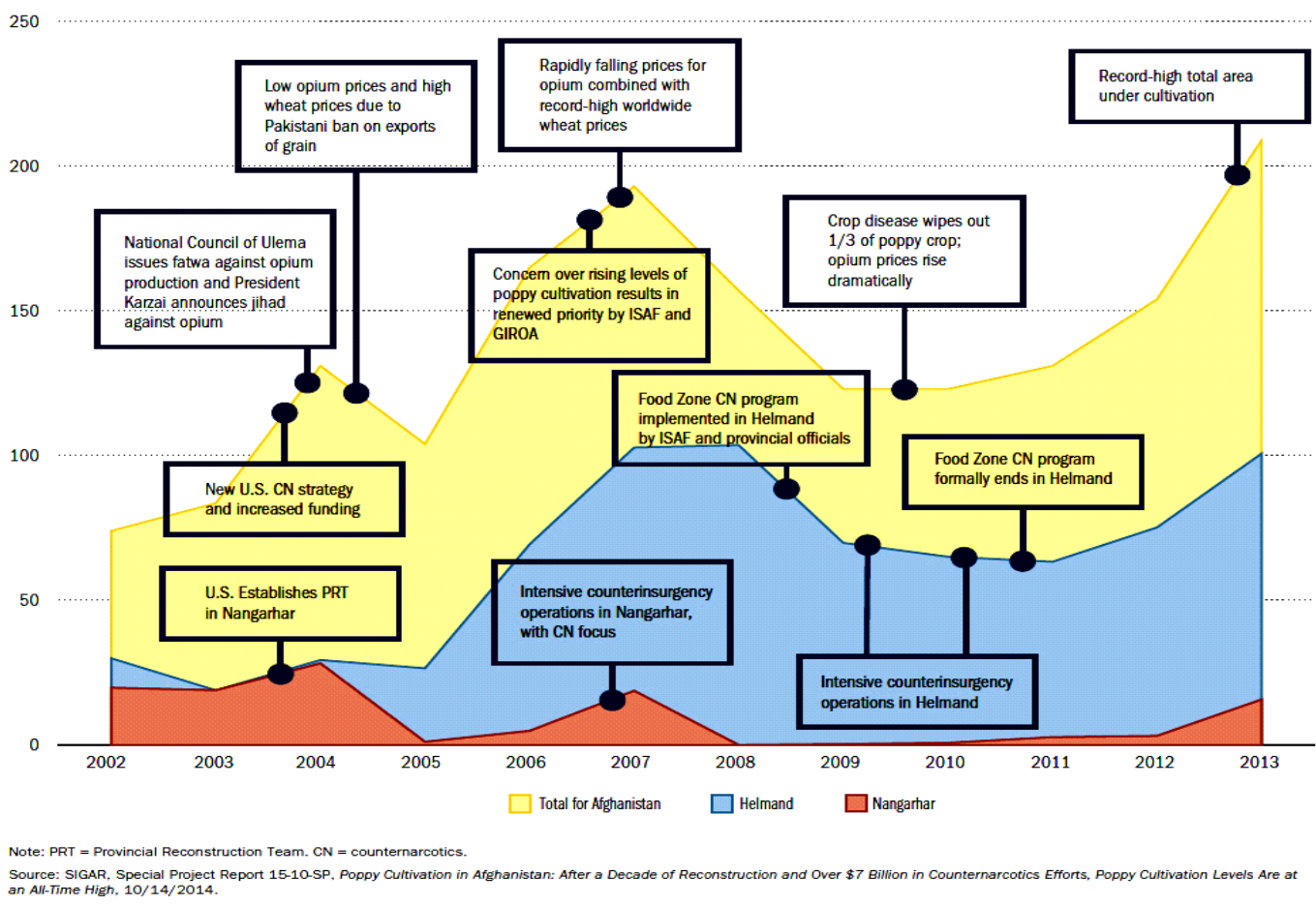

Figure no. 1 The fluctuation of opium poppy cultures between 2002-2013 [4] 
Previous operations, carried out by specially created military forces to eradicate the cultivation of opium poppy, have demonstrated that these actions should be undertaken annually and that the costs are very high. Poppy Eradication Force (PEF), which operated in Afghanistan in 20042009, managed the total destruction of 9946 hectares, and it is budgeted with USD 695.3 million, resulting in an approximate cost of $\$ 73,608$ / hectares [5].

Without this money and the necessary security forces, the implementation of the
FOOD ZONE type program remains uncertain and even the results achieved so far may be lost in the coming years.

\section{The Level of Preparedness of the Security Forces}

For 2015, the United States, the main donor to Afghanistan, has approved a budget of 4.29 billion dollars, most of it being intended to support Afghan security forces and to protect the population (Figure no. 2).

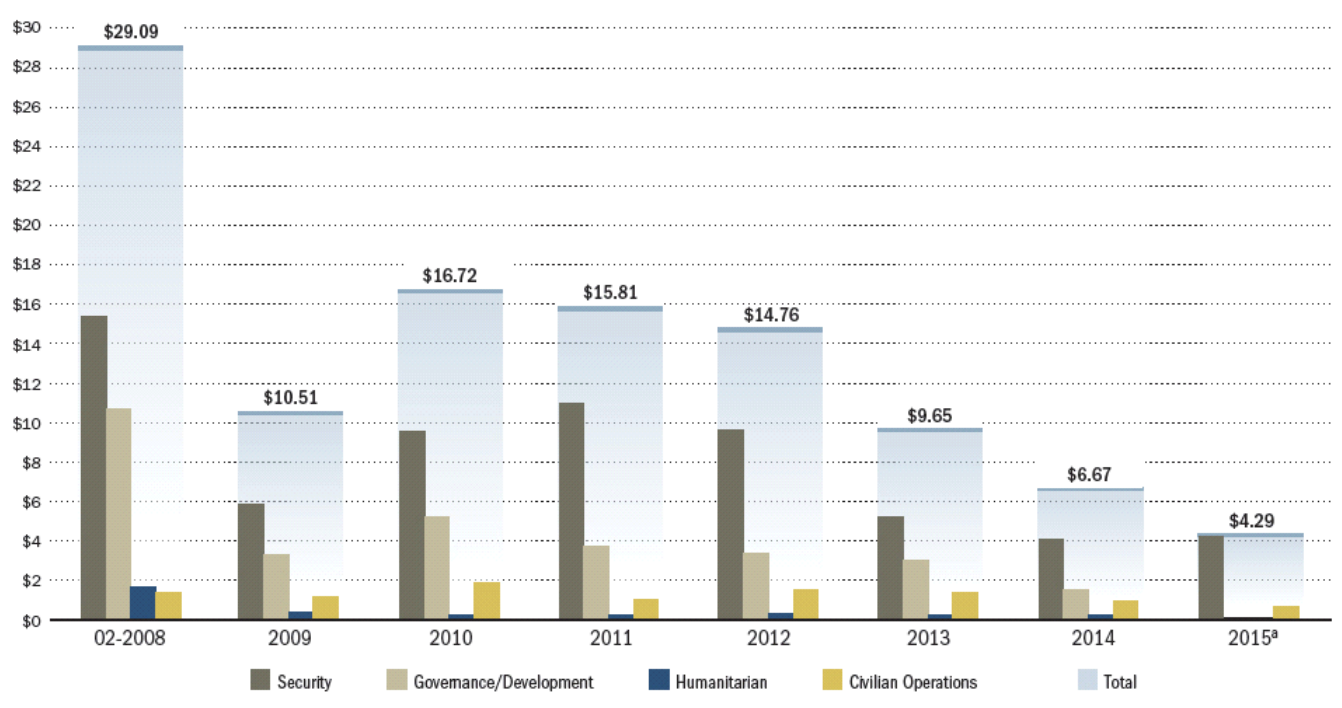

Figure no. 2 - the evolution of the external financial support allocated to Afghanistan in 2008-2015 [6]

The money allocated are necessary for reaching the limit of 352,000 troops, as opposed to the number of 338,856 recorded in September 2014, but also to equip the ANA forces or for the endowment and training the Afghan Air Force personnel [7].

In what regards the land forces, they are currently faced with two major problems: the defection of staff and the increase of the inside attacks, known as "Green on Blue". Their number increased from year to year, and in 2008 they accounted for $1 \%$ of Coalition losses in 2009 and 2010 by $2 \%$ in 2011 to $6 \%$ and in 2012 reached a record $15 \%$ of ISAF victims. Since 2008 until today, after Green on Blue attacks, a number of 144 militaries have died and other 183 were injured [8]. After such an attack, recorded on August 5, 2014, a US general was killed and 16 others were wounded inside the National Defence University in Kabul.

This niche identified by the insurgents in the selection process of the ANSF personnel allows the infiltration of sympathizers among the military or police forces, access to weapons, munitions and military bases, where the element of surprise favors the production of a large number of casualties.

In what concerns the Afghan Air Force, and according to NATO command centre in Afghanistan, in October of 2014, the Afghan fleet counted 101 combat ships, consisting of:

- $56 \mathrm{Mi}-17$ transport helicopters;

- 26 C-208 light transport aircraft; 
- 6 C-182 training aircraft;

- 5 MD-530F type helicopters;

- 5 Mi-35 attack helicopters;

- $3 \mathrm{C}-130 \mathrm{H}$ transport aircraft.

In 2015, the concluded contracts will provide 12 additional MD-530F helicopters and 20 Super Tucanos A29 aircraft, ideal for close air support or aerial reconnaissance actions.

The Afghan Air Force currently counts 131 pilots, all officers, who have completed specific training in Afghanistan or the US.

Their training and the endowment of the air fleet has enabled the increase of the reaction capability for medical evacuation, as reflected by the number of the missions carried out:

- 2012: 391 missions

- 2013: 1,540 missions

- 2014: 1,295 missions (just in the first 8 months of the year).

Despite these positive results, the Afghan air force depend $100 \%$ on the external financial investment needed to further equip the fleet, but also on the support needed for aircraft maintenance and pilot and support staff training.

An important aspect of the Afghan national security is the Afghan Local Police - ALP. Their organization and operation and the results obtained have led to the increase of the popular trust and support of these forces set up at community level. The reasons are easy to enumerate:

- ALP members are recruited from within the community, are known people, which does not allow the infiltration of insurgents or sympathizers or of members of foreign security agencies (the security service in Pakistan is often made accountable for the Green on Blue attacks registered among the Afghan armed forces);

- The enrolment is voluntary and the purpose is to protect their own families, properties and valuables, which increases the interest avoids the problem of desertions;

- Knowledge of the area, the approval of the tribal leaders and then support of the population gives them access to information which the ISAF and ANSF forces have searched for over 13 years, such as: the identity of the insurgent supporters, the supply routes used, operation modes etc.

The weakness of these security forces, available to local leaders and communities is the lack of funds for access to advanced weaponry and state-of-the-art military equipment (armoured equipment, means of ballistic protection, encrypted communication means etc) but also the low level of military training, their recruitment being carried out exclusively from the ranks of the local population or from people without experience in military actions.

\section{Conclusion}

The financial results recorded so far show that Afghanistan remains dependent on poppy crops, the amount of money obtained from drug trafficking surpassing the results obtained from alternative agricultural crops or from other economic domains. The withdrawal of ISAF forces will certainly increase the areas of cultivated land for this purpose and this will result in the immediate access of anti-government groups to the funds needed to take over the central power in Kabul.

The only way to avoid the return of Afghanistan to the insecurity environmental conditions existing in 2001 is to continue offering financial and military support to the regime currently led by the new president Ashraf Ghani Ahmadzai. His declaration, after being invested in 2014, "The main demand of the Afghan people is security. We're tired of this war" [9] and the attempt to call the representatives of the Taliban party to the negotiating table shows that a change is desired. Afghanistan's economic recovery depends on attracting foreign investors, currently kept at bay by the existing uncertainty. Mobilizing the masses and the support of the population in this struggle for peace may be the key of the success and the direction that the new president must take. The cooperation of the provincial tribal leaders with the new Government of the Islamic Republic of 
Afghanistan may lead to a mass coalition against violence, to a common vote of the population against insecurity and against all those promoting it, regardless of the political, tribal, ethnic or religious affiliation.

\section{References}

1. Kenneth Katzman, Afghanistan: Post-Taliban Governance, Security, and U.S. Policy, 20.01.2015, available at https:/www.fas.org/sgp/crs/row/RL30588.pdf

2. SIGAR - (Special Inspector General for Afghanistan Reconstruction 3rd trimester/2014).

3. Ibidem

4. Ibidem

5. Ibidem

6. SIGAR - (Special Inspector General for Afghanistan Reconstruction 1st trimester/2015), 79

7. SIGAR - (Special Inspector General for Afghanistan Reconstruction 3rd trimester/2014), 92

8. Bill Roggio and Lisa Lundquist, Green-on-blue attacks in Afghanistan: the data, available at: http://www.longwarjournal.org/archives/2012/08/green-on-blue attack.php

9. http://www.usatoday.com/story/news/world/2014/09/30/afghan-us-security-pact/16467441/ 